Thorax, 1979, 34, 599-605

\title{
Surgery of the ascending aorta: five years' experience at a regional cardiac centre
}

\author{
P G REASBECK, J L MONRO, J K ROSS, N CONWAY, AND A M JOHNSON
}

From the Wessex Cardiac and Thoracic Centre, Southampton Western Hospital, Southampton, UK

ABSTRACT Between 1972 and 1978, 31 patients underwent replacement of the ascending aorta, with or without aortic valve surgery, at the Wessex Regional Cardiac Centre. The commonest indications for operation were aneurysmal dilatation of the ascending aorta causing aortic regurgitation and acute dissection of the ascending aorta. Eleven of the 31 patients had features of Marfan's syndrome. The overall hospital mortality was $19 \cdot 4 \%$, a figure comparable with those reported in other series; ventricular failure secondary to ischaemia during operation was the commonest cause of death. The long-term symptomatic results were excellent, except in the two patients who underwent resuspension of the aortic valve for aortic regurgitation associated with acute dissections. For aneurysms of the ascending aorta with associated aortic regurgitation, replacement of the valve and ascending aorta with a combined valve prosthesis and synthetic tube graft, with reimplantation of the coronary ostia, is the procedure of choice if the aortic valve ring is diseased. Experience to date indicates that replacement of the ascending aorta and aortic valve with separate prostheses, leaving the coronary ostia undisturbed, is a satisfactory alternative provided the aortic annulus is of suitable size and quality; this is more likely to be the case in dissections than in aneurysmal dilatation of the ascending aorta. Replacement of the ascending aorta may also be indicated in some cases of dilatation of the ascending aorta secondary to aortic valve disease if the aortic wall is unusually thin.

Replacement of the ascending aorta may be required when treating aneurysmal dilatation or dissection. Aneurysmal dilatation of the ascending aorta often extends proximally to affect the aortic valve ring and to cause aortic regurgitation, a pathological complex designated by Ellis et al (1961) as annuloaortic ectasia. Cystic medial necrosis is said to be a common histological finding in the affected areas (Baer et al, 1943), and the stigmata of Marfan's syndrome are often present (McKusick, 1955).

Surgical treatment of annuloaortic ectasia may be needed when symptoms of aortic regurgitation appear, or an ascending aortic aneurysm is discovered. Without treatment, a progression to congestive heart failure, aortic rupture, or dissection may occur (Roark, 1959). In 1956 Bahnson and Nelson attempted to arrest this progression by resecting part of the anterolateral ascending aortic wall and wrapping the reconstituted vessel with nylon cloth. Later, Bahnson and Spencer (1960) described the excision of the aneurysmal segment of ascending aorta and its replacement by a Teflon prosthesis, using cardiopulmonary bypass. Technique was further improved by correction of the aortic regurgitation by bicuspidisation of the valve (Muller et al, 1960), or simultaneous replacement of the aortic valve with a prosthesis and of the ascending aorta distal to the coronary ostia with a Teflon graft (Wheat et al, 1964). Both these operations, however, left a diseased segment of aorta between the graft and the aortic valve. In addition, the proximal aortic remnant is often thin and friable, rendering suturing difficult and predisposing to haemorrhage from the proximal anastomosis between the aorta and the graft (Ferlic et al, 1967; Symbas et al, 1970). In 1968 Bentall and DeBono first described a method by which these difficulties could be overcome. They replaced the entire ascending aorta and aortic valve with a composite graft made up of a Dacron tube with a ball valve prosthesis incorporated into the proximal end. The coronary ostia were anastomosed to the graft at a suitable level above the prosthetic aortic valve. 
Several workers have subsequently used this method (here referred to as composite replacement of the ascending aorta) with occasional modifications and considerable success (Edwards and Kerr, 1970; Crosby et al, 1973; Helseth et al, 1974; Zubiate and Kay, 1976). In those series repurted to date the collective operative mortality has been $13.2 \%$ (Blanco et al, 1976; Hashimoto et al, 1976; Zubiate and Kay, 1976; Brøyn et al, 1977; Zingone et al, 1977; Mayer et al, 1978).

After some initial controversy (De Bakey et al, 1965; Lindsay and Hurst, 1967, 1968; Wheat et al, 1969), it is now generally accepted that dissections of the ascending aorta are better treated surgically than medically (Lindsay and Hurst, 1968; Daily et al, 1970; Applebaum et al, 1976; D'Allaines et al, 1977; Seybold-Epting et al, 1977), particularly as they are often complicated by aortic regurgitation, coronary artery dissections, and cardiac tamponade. The technique of ascending aortic replacement, combined where necessary with replacement or resuspension of the aortic valve, is similar to that used in annuloaortic ectasia, but the operative mortality is higher: it varies from about $15 \%$ to $40 \%$, and is lower in chronic than acute dissections (Applebaum et al, 1976; D'Allaines et al, 1977; Seybold-Epting et al, 1977).

We review our experience of ascending aortic replacement for dissection or aneurysmal dilatation in the light of these figures.

\section{Methods and materials}

From December 1972 to May 197831 patients underwent prosthetic replacement of the ascending aorta at the Wessex Regional Cardiac Centre, of whom 29 had undergone angiocardiography and aortography. The condition of the remaining two, both with clinically obvious aortic dissection, was so poor that immediate operation was undertaken without preliminary catheter studies. The indications for operation are shown in table 1 . Of the 13 patients with dissecting aneurysms of the ascending aorta, 11 had associated aortic regurgitation and four the stigmata and histological features of Marfan's syndrome. In three patients the diagnosis of ascending aortic dissection was unsuspected before operation, which was undertaken to correct other lesions. The mean age of the entire group was 49.8 (range 25-67). A total of 11 patients had the clinical or histological features of Marfan's syndrome, and their mean age $(42.5)$ was significantly lower $(P<0.005)$ than that of the remainder (53.9).

In all cases the mediastinum was approached through a median sternotomy and cardio-
Table 1 Indications for operation. For patients with dissecting aneurysms affecting the ascending aorta the mean interval between onset of symptoms and operation is given in column three

\begin{tabular}{lcl}
\hline Diagnosis & $\begin{array}{l}\text { No of } \\
\text { patients }\end{array}$ & $\begin{array}{l}\text { Mean interval between } \\
\text { onset of symptons and } \\
\text { operation }\end{array}$ \\
\hline $\begin{array}{l}\text { Acute dissection } \\
\text { Subacute dissection }\end{array}$ & 7 & $\begin{array}{l}22 \cdot 4 \text { hours } \\
\text { Chronic dissection }\end{array}$ \\
$\begin{array}{l}\text { Annuloaortic ectasia } \\
\begin{array}{l}\text { Ascending aortic aneurysm } \\
\text { associated with infective }\end{array}\end{array}$ & 3 & $\begin{array}{l}13 \cdot 2 \text { days } \\
\text { endocarditis arising on aortic } \\
\text { valve prosthesis }\end{array}$ \\
$\begin{array}{l}\text { Atherosclerotic ascending } \\
\text { aortic aneurysm }\end{array}$ & 12 & \\
$\begin{array}{l}\text { Syphilitic aortic aneurysm } \\
\text { +aortic regurgitation }\end{array}$ & 1 & \\
$\begin{array}{l}\text { Ascending aortic dissection } \\
\text { discovered during other } \\
\text { procedure }\end{array}$ & 1 & \\
\hline
\end{tabular}

pulmonary bypass instituted via venous cannulae inserted through the right atrium, and an arterial cannula in the femoral artery. Moderate wholebody hypothermia of $28-30^{\circ} \mathrm{C}$ with continuous coronary perfusion was used in all patients up to October 1977. Since then four patients have had operations under moderate whole-body hypothermia combined with intermittent perfusion of 3 the coronary arteries with cold cardioplegic solution combined with topical cooling by pericardial irrigation. The ascending aorta was replaced by a crimped, woven Dacron graft (diameter 30 or $35 \mathrm{~mm}$ ) and the aortic valve was dealt with in various ways as shown (table 2).

Eleven patients underwent composite replacement of the aortic valve and ascending aorta by a Björk-Shiley prosthesis incorporated into a Dacron graft, the coronary ostia being anastomosed to the 윽 graft in the manner described by Bentall (Bentall $\rightarrow$ and DeBono, 1968; Singh and Bentall, 1972). In three of these the Dacron graft was placed inside $N$ the incised aneurysm and the edges of the coronary ostia anastomosed with continuous Prolene sutures 0 to holes cut in the graft just above the valve $\omega$ prosthesis. In the remainder the aneurysm was excised except for a cuff of aortic wall surrounding $\varrho$ each coronary ostium; each cuff was then anastomosed with continuous Prolene to an open- :ing cut in the Dacron graft. Two other patients underwent modifications of this procedure. In $\frac{\vec{D}}{\mathbb{D}}$ one, whose aortic valve ring had disintegrated as a $\cong$ result of severe infective endocarditis, the Dacron $\mathbb{Q}$ graft incorporating a Björk-Shiley valve was anastomosed proximally below the aortic valve 
Table 2 Operations performed according to diagnosis

\begin{tabular}{|c|c|c|c|c|c|}
\hline Diagnosis & $\begin{array}{l}\text { Composite } \\
\text { replacement }\end{array}$ & $\begin{array}{l}\text { Modified composite } \\
\text { replacement }\end{array}$ & $\begin{array}{l}\text { Separate aortic } \\
\text { valve and ascending } \\
\text { aortic replacement }\end{array}$ & $\begin{array}{l}\text { Aortic replacement } \\
\text { +aortic valve } \\
\text { resuspension }\end{array}$ & $\begin{array}{l}\text { Ascending aortic } \\
\text { replacement only }\end{array}$ \\
\hline Acute dissection & 0 & 0 & 5 & 1 & 1 \\
\hline Subacute dissection & 1 & 0 & $\mathbf{0}$ & 1 & 1 \\
\hline Chronic dissection & 1 & 0 & 2 & 0 & 0 \\
\hline Annuloaortic ectasia & 8 & 1 & 3 & 0 & 0 \\
\hline $\begin{array}{l}\text { Dissection discovered during other } \\
\text { operative procedure }\end{array}$ & 0 & 0 & 1 & 0 & 2 \\
\hline Other & 1 & 1 & 0 & 0 & 1 \\
\hline Total & 11 & 2 & 11 & 2 & 5 \\
\hline
\end{tabular}

ring to the anterior leaflet of the mitral valve. In the second, a patient with annuloaortic ectasia, the right coronary ostium was anastomosed to a Dacron graft containing a Starr-Edwards valve prosthesis, but the anastomosis between the graft and the aortic valve ring was made distal to the left coronary ostium. Eleven patients underwent replacement of the ascending aorta and aortic valve with separate prostheses (six Björk-Shiley, three Braunwald-Cutter, and two Starr-Edwards valves). Five patients, four of whom had dissections, underwent replacement of the ascending aorta alone (one with a coronary artery bypass graft from the prosthesis to the left anterior descending vessel), and two patients with dissecting aneurysms underwent replacement of the ascending aorta with resuspension of the aortic valve cusps to abolish regurgitation. In most cases histological examination of material from the diseased aorta was carried out (table 3).

The mean duration of cardiopulmonary bypass was 143 minutes for the whole group; for the six patients who died within one month of operation this rose to 217 minutes $(P<0.005)$. Only two patients required catecholamine support after operation; both had undergone composite replacement for annuloaortic ectasia.

\section{Results}

\section{HOSPITAL MORTALITY}

Six patients died within one month of operation, giving an overall hospital mortality of $19.4 \%$. In tables 4 and 5 this is analysed according to preoperative diagnosis and operation performed. Two of these patients developed acute iatrogenic dissections of the ascending aorta as a result of aortic cannulation in preparation for replacement of the mitral and aortic valves respectively. In both cases the ascending aorta was enlarged. After ascending aortic replacement one developed a stone heart syndrome from severe myocardial ischaemia, and died during the operation. The other was well until the tenth postoperative day, when he suffered a sudden cardiac arrest from which he could not be resuscitated. Necropsy showed a large recent infarct of the left ventricle and cystic medial necrosis of the aorta. A third patient undergoing mitral valve replacement was found at operation to have sustained an acute iatrogenic dissection of the ascending aorta at preoperative cardiac catheterisation. The ascending aorta was replaced and a saphenous vein bypass graft inserted from the aortic prosthesis to the left anterior descending coronary artery, which was occluded proximally

Table 3 Histological findings

\begin{tabular}{|c|c|c|c|c|c|}
\hline Diagnosis & Marfan's syndrome & Syphilis & Atheroma & $\begin{array}{l}\text { Non-specific } \\
\text { degeneration or } \\
\text { inflammation }\end{array}$ & Normal \\
\hline Acute dissection & 2 & 0 & 0 & 4 & 0 \\
\hline Subacute dissection & 2 & 0 & 0 & 0 & 0 \\
\hline Chronic dissection & 1 & 1 & 0 & 1 & 0 \\
\hline Annuloaortic ectasia & 2 & 1 & 1 & 4 & 1 \\
\hline $\begin{array}{l}\text { Dissection discovered during other } \\
\text { operative procedure }\end{array}$ & 1 & 0 & 0 & 2 & 0 \\
\hline Other & 0 & 1 & 0 & 0 & 0 \\
\hline
\end{tabular}

No histological examination was carried out in seven patients. 
Table 4 Mortality according to diagnosis

\begin{tabular}{llll}
\hline Diagnosis & $\begin{array}{l}\text { No of } \\
\text { patients } \\
\text { undergoing } \\
\text { operation }\end{array}$ & $\begin{array}{l}\text { Operative } \\
\text { deaths }\end{array}$ & $\%$ mortality \\
\hline Acute dissection & 7 & 1 & $14 \cdot 3$ \\
Subacute dissection & 3 & 0 & 0 \\
Chronic dissection & 3 & 0 & 0 \\
Annuloaortic ectasia & 12 & 1 & $8 \cdot 3$ \\
$\begin{array}{l}\text { Dissection discovered } \\
\text { during other procedure }\end{array}$ & 3 & 3 & 100 \\
Other & 3 & 1 & 33 \\
\hline
\end{tabular}

Table 5 Mortality according to operative procedure

\begin{tabular}{llll}
\hline Operation & $\begin{array}{l}\text { No of } \\
\text { patients } \\
\text { undergoing } \\
\text { operation }\end{array}$ & $\begin{array}{l}\text { Operative } \\
\text { deaths }\end{array}$ & \% mortality \\
\hline $\begin{array}{l}\text { Composite replacement } \\
\begin{array}{l}\text { Modified composite } \\
\text { replacement }\end{array}\end{array}$ & 11 & 1 & $9 \cdot 1$ \\
$\begin{array}{l}\text { Aortic replacement } \\
\text { +aortic valve } \\
\text { resuspension }\end{array}$ & 2 & 1 & 50 \\
$\begin{array}{l}\text { Separate aortic valve } \\
\text { and ascending aortic } \\
\text { replacement }\end{array}$ & 11 & 0 & 0 \\
$\begin{array}{l}\text { Ascending aortic } \\
\text { replacement only }\end{array}$ & 5 & 3 & $9 \cdot 1$ \\
\hline
\end{tabular}

by the aortic dissection. However, cardiopulmonary bypass could not be discontinued because of severe ischaemic myocardial damage, and the patient died. The fourth patient was undergoing his fourth aortic valve replacement for severe aortic regurgitation caused by infective endocarditis. At operation the aortic annulus was found to have disintegrated completely, and a Dacron graft incorporating a Björk-Shiley valve prosthesis was anastomosed to the tissues surrounding and below the annulus. There followed severe and uncontrollable bleeding from the back of the graft and lower anastomosis, from which he died. The fifth patient, who had severe chronic obstructive airways disease, underwent an emergency operation for severe aortic regurgitation with annuloaortic ectasia. The operation was technically uneventful but he died on the 25th postoperative day from chronic respiratory failure. The sixth underwent emergency ascending aortic replacement for an acute dissecting aneurysm. He was anuric for several hours before operation and immediately before the procedure developed acute cardiac tamponade. After the operation he was noted to have severe neurological damage and to be unable to maintaing an adequate cardiac output despite inotropic음 support. He died 12 hours later.

\section{LATE MORTALITY}

There was one late death-a 48-year-old woman ${ }^{\text {क }}$ with Marfan's syndrome who underwent an? emergency operation for an acute aortic dissection. $\overrightarrow{\vec{\omega}}$ She was well when seen two months after opera- $\stackrel{\omega}{\omega}$ tion, but she died of bronchopneumonia and $\vec{x}$ congestive heart failure one month later.

\section{FOLLOW-UP AND MORBIDITY}

Two patients were referred from centres outside $\mathscr{C}$ Britain and on returning home were lost to follow-은 up. For the remaining 22 survivors the mean duration of follow-up was 27.8 months (range $O$ 1-60 months).

Two patients with Marfan's syndrome who underwent replacement of the aortic valve and ascending aorta for acute dissection subsequently $\vec{\theta}$ developed other aortic aneurysms. The first, aged 29, developed a type III dissection one month after operation, which was treated medically, and an aneurysm of the abdominal aorta two years later that was successfully resected. He was well 31 months after his first operation. The second, $\mathbb{Q}$ who had developed chronic mediastinal sepsis $\overrightarrow{\vec{F}}$ after his operation, had positive blood cultures 22 months after operation, and at the same time was found to have developed an aneurysm of the abdominal aorta. Mediastinal exploration showed an abscess surrounding the lower end of the aortic prosthesis; this was drained, and his bacteraemia subsided. The abdominal aneurysm was successfully resected one month later, and he was well 53 months after the original operation.

Both patients who underwent aortic valve resuspension in conjunction with ascending aortic replacement later developed recurrent aortic regurgitation. One of these underwent xenograft aortic valve replacement three months later and was well at seven months, while the other remained well on medical treatment when last seen at an outpatient clinic 21 months after operation.

All other patients were well at follow-up with the exception of a 51-year-old man with longstanding symptomatic chronic obstructive airways disease.

\section{Discussion}

Our overall operative mortality of $19.4 \%$ is heavily loaded by the deaths of all three patients in whom a dissection of the ascending aorta appeared during operation for other lesions: these were 
iatrogenic dissections, one having occurred at cardiac catheterisation and the other two at aortic cannulation. Possibly this high incidence of iatrogenic dissection is related to underlying connective tissue defects; one of these three proved to have cystic medial necrosis of the aorta, while another had developed a fistula between the left ventricle and the right atrium after mitral valve replacement, suggesting poor quality connective tissue in this area. This high incidence of dissection at aortic cannulation is certainly at variance with our experience in other patients; in a total of 1840 cardiopulmonary bypass procedures performed at this centre during the period covered by this survey, these two dissections were the only ones so produced. Taylor and Effler (1977) quote an incidence of one iatrogenic dissection in 8000 aortic cannulations at the Cleveland Clinic but note that the risk is much higher in Marfan's syndrome, in the presence of cystic medial necrosis, and in cases in which the aorta is heavily calcified or thin and of poor quality. Applebaum et al (1976) specifically excluded patients with iatrogenic dissections when reporting their experience of surgical treatment of dissecting aneurysms of the aorta, and it seems to us that these represent a subgroup at particularly high risk. This has also been the experience of other workers (Elliot and Roe, 1965; Kay et al, 1966), although Carey et al (1977) recorded six survivals out of seven cases in which aortic dissection appeared during cardiopulmonary bypass; in no case was the ascending aorta repaired or replaced.

Whether or not it is justifiable to regard this as a high-risk subgroup, it seems reasonable for the purpose of comparison to follow the example of Applebaum et al (1976) in considering it separately. If this is done our results for aortic replacement for ascending aortic dissections $(7.7 \%$ overall hospital mortality) compare favourably with those of others, although the numbers concerned are small. Even if the three patients with iatrogenic dissections are included in this group the overall operative mortality for ascending aortic dissections is $25 \%$, a figure comparable with those reported by others (De Bakey et al, 1965; Applebaum et al, 1976; Brøyn et al, 1977; Seybold-Epting et al, 1977).

Perhaps more significant in relation to the total number of cases previously reported is our experience of composite replacement of the ascending aorta; our mortality of $9.1 \%$ again compares favourably with the results previously reported by others. If the additional two cases who underwent modifications of this procedure are included this operative mortality rises to $15.4 \%$, a figure com- parable with the mortality in previous series $(13 \cdot 2 \%)$.

Unlike Zubiate and Kay (1976), we have not experienced any particular difficulty in reimplanting the coronary ostia because of friability of the aortic wall surrounding each ostium, even in cases of acute dissection. We have had to use saphenous vein grafting between the Dacron prosthesis and the coronary arteries on only one occasion.

In most cases of dissection the proximal aorta has been of adequate quality to allow separate replacement of the aortic valve and ascending aorta. In most patients with annuloaortic ectasia, on the other hand, we have considered composite replacement to be the procedure of choice because of the risk of progression of disease in any residual proximal aorta. Our good results to date from separate replacement of the ascending aorta and valve in those without annuloaortic ectasia suggest that this technique is a satisfactory alternative to composite replacement when the aortic annulus is of suitable size and quality.

Our poor long-term results after resuspension of the aortic valve are in agreement with those of Seybold-Epting et al (1977), who have abandoned this technique because of the high incidence of postoperative aortic regurgitation. Like them, we have been unable to reproduce the good results obtained by Gerbode $e t$ al (1966), Applebaum et al (1976), and Yacoub et al (1976) from repair of the aortic valve.

As in other series (Blanco et al, 1976; Hashimoto et al, 1976), intraoperative bleeding and postoperative arrhythmias have contributed to our operative mortality. In this small series, however, the commonest cause of death in the perioperative period was inability to discontinue cardiopulmonary bypass as a result of ischaemic myocardial damage. Myocardial ischaemia was also responsible for at least one death shortly after operation. Difficulty in maintaining adequate coronary perfusion during operation has not been rare in these patients, particularly in cases of ascending aortic dissection, which may extend proximally to affect and occlude the coronary ostia. This problem is compounded by the fact that preoperative coronary arteriography is technically difficult in these patients, so that the anticipation of coronary arterial narrowing from dissection or coincidental atherosclerosis may be impossible. The use of deep cardiac hypothermia with cold cardioplegic solution infused intermittently into the aortic root or coronary ostia is becoming routine at this centre as an alternative to continuous coronary perfusion with oxygenated blood. In addition to eliminating the difficulties 
associated with continuous coronary perfusion in the presence of coronary artery disease, we have found that this renders the formation of the proximal anastomosis and reimplantation of the coronary ostia technically very much easier

So far we have been unable to define a limiting aortic diameter beyond which ascending aortic replacement becomes mandatory in the presence of dilatation of the ascending aorta. Because of the difficulties and inaccuracies inherent in such a study, we have not carried out a retrospective analysis of the 500 aortic valve replacements performed at this centre during the period of the present survey. We are aware, however, of at least two patients with relatively mild post-stenotic dilatation of the ascending aorta in whom the aortic disease has progressed after replacement of the aortic valve alone. The first, a 64-year-old man, collapsed and died suddenly when his ascending aorta ruptured eight months after insertion of a Starr-Edwards aortic valve prosthesis. The second, a 61-year-old woman whose ascending aorta was $4 \mathrm{~cm}$ in diameter at operation, remains asymptomatic two-and-a-half years after aortic valve replacement with a Starr-Edwards prosthesis, but serial chest radiographs have shown a progressive increase in the width of her ascending aorta. It may be that the true incidence of continuing disease in the ascending aorta after aortic valve replacement is higher than these figures indicate; it may also be relevant that both these patients received a caged-ball prosthesis, in which the jet of blood emerging through the valve is directed laterally, thus imposing a greater pulsatile strain on the aortic root than that present after insertion of a pivoting-disc prosthesis. Nevertheless, our experience with these patients suggests the possibility that replacement of the ascending aorta as well as the aortic valve may involve less risk than aortic valve replacement alone in some cases of ascending aortic dilatation secondary to aortic valve disease, especially if the aortic wall is noted to be unusually thin. Prospective studies will be required to define an upper limit of "normal" aortic diameter above which replacement of the ascending aorta is necessary in cases of poststenotic dilatation with excessive thinning of the aortic wall but with persistence of the aortic supravalvar ridge. In the meantime it may be advisable to avoid the use of caged-ball prostheses for aortic valve replacement in the presence of any degree of ascending aortic dilatation.
References

Applebaum, A, Karp, R B, and Kirklin, J W (1976). Ascending vs descending aortic dissections. Annals $\frac{\omega}{7}$ of Surgery, 183, 296-300.

Baer, R W, Taussig, H G, and Oppenheimer, E H (1943). Congenital aneurysmal dilatation of the aorta associated with arachnodactyly. Bulletin of $\vec{\circ}$ Johns Hopkins Hospital, 72, 309-331.

Bahnson, H T, and Nelson, A R (1956). Cystic medial ${ }_{\mathscr{\sigma}}$ necrosis as a cause of localised aortic aneurysms amenable to surgical treatment. Annals of Surgery, 144, 519-529.

Bahnson, H T, and Spencer, F C (1960). Excision of $\mathrm{c}$ aneurysm of the ascending aorta with prosthetic of replacement during cardiopulmonary bypass. Annals 8 of Surgery, 151, 879-890.

Bentall, H, and DeBono, A (1968). A technique for complete replacement of the ascending aorta.

Thorax, 23, 338-339.
Blanco, G, Adam, A, and Carlo, V (1976). A con- $\frac{0}{0}$ trolled surgical approach to annulo-aortic ectasia. Annals of Surgery, 183, 174-178.

Brøyn, T, Froysaker, T, and Hall, K V (1977). ढै Aneurysm of the ascending aorta with aortic valve incompetence. Scandinavian Journal of Thoracic and Cardiovascular Surgery, 11, 221-223.

Carey, J S, Skow, J R, and Scott, C (1977). Retrograde aortic dissection during cardiopulmonary by- 응 pass. "Non-operative" management. Annals of $\stackrel{\mathbb{Q}}{\mathcal{Q}}$ Thoracic Surgery, 24, $44-48$.

Crosby, I K, Ashcraft, W C, and Reed, W A (1973). Surgery of the proximal aorta in Marfan's syndrome. Journal of Thoracic and Cardiovascular Surgery, 66, 秂 75-81.

Daily, P O, Trueblood, H W, Stinson, E B, Wuerflein, R D, and Shumway, N E (1970). The management 응 of acute aortic dissections. Annals of Thoracic Sur- $\stackrel{x}{\times}$ gery, 10, 237-247.

D'Allaines, C, Blondeau, P, Piwnica, A, Carpentier, A, Soyer, R, Deloche, A, Farge, C, Relland, J Y, ᄋ̊ and Dubost, C (1977). Surgery for aortic dissection; 53 operated cases with 32 in the acute phase. Journal of Cardiovascular Surgery, 18, 261-266.

De Bakey, M E, Henly, W S, Cooley, D A, Morris, ? G C jun, Crawford, E S, and Beall, A C jun (1965). Surgical management of dissecting aneurysms of the $N$ aorta. Journal of Thoracic and Cardiovascular Surgery, 49, 130-149.

Edwards, W S, and Kerr, A R (1970). A safer tech- N nique for replacement of the entire ascending aorta and aortic valve. Journal of Thoracic and Cardio- 0 vascular Surgery, 59, 837-839.

Elliot, D P, and Roe, B B (1965). Aortic dissection during cardiopulmonary bypass. Journal of Thoracic and Cardiovascular Surgery, 50, 357-363.

Ellis P R, Cooley, D A, and De Bakey, M E (1961). Clinical considerations and surgical treatment of annulo-aortic ectasia. Journal of Thoracic and Cardiovascular Surgery, 42, 363-370.

Ferlic, R M, Goott, B, Edwards, J E, and Lillehei,

\section{.}


C W (1967). Aortic valvular insufficiency associated with cystic medial necrosis. Annals of Surgery, 165, 1-9.

Gerbode, F, Semb, G S, Hill, J D, and Kerth, W J (1966). Aneurysms of the ascending aorta. A method of reconstructing the aortic root. Annals of Thoracic Surgery, 2, 525-531.

Hashimoto, A, Kitamura, N, Koyanagi, H, and Konno, S (1976). Surgical treatment of annuloaortic ectasia. Journal of Cardiovascular Surgery, 17, 240-247.

Helseth, H K, Haglin, J J, Stenlund, R R, and Peterson, C R (1974). Evaluation of composite graft replacement of the aortic root and ascending aorta. Annals of Thoracic Surgery, 18, 138-141.

Kay, J H, Dykstra, P C, and Tsujo, H K (1966). Retrograde ilio-aortic dissection: a complication of common femoral arterial perfusion during open heart surgery. American Journal of Surgery, 111, $464-468$.

Lindsay, J jun, and Hurst, J W (1967). Clinical features and prognosis in dissecting aneurysm of the aorta. Circulation, 35, 880-888.

Lindsay, J jun, and Hurst, J W (1968). Drug therapy of dissecting aortic aneurysms. Circulation, 37, 216-219.

Mayer, T E jun, Lindsay, W G, Wang, Y, Jorgenson, C, and Nicoloff, D M (1978). Composite replacement of the aortic valve and ascending aorta. Reported at 58th Annual Meeting of the American Association for Thoracic Surgery, New Orleans.

McKusick, V A (1955). The cardiovascular aspects of Marfan's syndrome; a heritable disorder of connective tissue. Circulation, 11, 321-342.

Muller, H W jun, Dammann, J F, and Warren, W D (1960). Surgical correction of cardiovascular deformities in Marfan's syndrome. Annals of Surgery, 152, 506-517.

Roark, J W (1959). The Marfan syndrome. Archives of Internal Medicine, 103, 123-132.

Seybold-Epting, W, Meyer, J, Hallman, G L, and
Cooley, D A (1977). Surgical treatment of acute dissecting aneurysm of the ascending aorta. Journal of Cardiovascular Surgery, 18, 43-48.

Singh, M P, and Bentall, H H (1972). Complete replacement of the ascending aorta and the aortic valve for the treatment of aortic aneurysm. Journal of Thoracic and Cardiovascular Surgery, 63, 218225.

Symbas, P N, Baldwin, B J, Silverman, M E, and Galambos, J T (1970). Marfan's syndrome with aneurysm of ascending aorta and aortic regurgitation. American Journal of Cardiology, 25, 483-489.

Taylor, P C, and Effler, D B (1977). Management of cannulation for cardiopulmonary bypass in patients with adult acquired heart disease. Surgical Clinics of North America, 55, 1205-1215.

Wheat, M R jun, Harris, P D, Malm, J R, Kaiser, G, Bowman, F O jun, and Palmer, R F (1969). Acute dissecting aneurysms of the aorta. Journal of Thoracic and Cardiovascular Surgery, 58, 344-351.

Wheat, $\mathbf{M} \mathbf{R}$ jun, Wilson, $\mathbf{J} \mathbf{R}$, and Bartley, $\mathbf{T} \mathbf{D}$ (1964). Successful replacement of the entire ascending aorta and aortic valve. Journal of the American Medical Association, 188, 717-719.

Yacoub, M, Gula, G, and Pomerance, A (1976). Surgical treatment of aneurysms of the ascending aorta. British Heart Journal, 38, 874.

Zingone, B, Vaccari, M, and Camerini, F (1977). Surgical treatment of aortic valve insufficiency due to annulo-aortic ectasia. Journal of Cardiovascular Surgery, 18, 581-589.

Zubiate, P, and Kay, J H (1976). Surgical treatment of aneurysm of the ascending aorta with aortic insufficiency and marked displacement of the coronary ostia. Journal of Thoracic and Cardiovascular Surgery, 71, 415-421.

Requests for reprints to: Mr P G Reasbeck, Department of Surgery, University of Otago, PO Box 913, Dunedin, New Zealand. 